\title{
Naive Realism for Unconscious Perceptions
}

\author{
Ori Beck*
}

\begin{abstract}
Unconscious perceptions (i.e., person-level perceptions that lack phenomenal character) have recently become a focal point in the debate for and against naive realism. In this paper I defend the naive realist side. More specifically, I use an idea of Martin's to develop a new version of naive realism - neuro-computational naive realism. I argue that neuro-computational naive realism offers a uniform treatment of both conscious and unconscious perceptions. I also argue that it accommodates the possibility of phenomenally different conscious perceptions of the same items, and that it can answer a further challenge to naive realism raised by Berger and Nanay.
\end{abstract}

\section{Introduction}

Unconscious perceptions (i.e., person-level perceptions that lack phenomenal character) have recently become a focal point in the debate for and against naive realism. On one side of this debate, Berger and Nanay (2016) have argued that the existence of unconscious perceptions undermines naive realism. ${ }^{1}$ Berger and Nanay consider three ways in which naive realists might try to address the phenomenon of unconscious perceptions, but they find them all objectionable. On the other side of the debate, Anaya and Clarke (2017) believe that Berger and Nanay have failed to show that unconscious perceptions pose a problem for naive realism. Naive realists, they say, can reasonably try to address the topic of unconscious perceptions in any of the ways that Berger and Nanay consider.

I agree with Anaya and Clarke's assessment. But I also agree with Anaya and Clarke (2017, p. 5-6) that the discussion cannot end with naive realists taking a purely defensive stance. Rather, naive realists should constructively put forward their views about unconscious perceptions. That is the task this paper undertakes. The paper develops a version of naive realism called "neuro-computational naive realism". Neuro-computational naive realism can accommodate not only unconscious perceptions, but also phenomenally different conscious perceptions of the

"I am indebted Jacob Berger, Bence Nanay, Adam Pautz, Henry Taylor, and to the participants of the European Society for Philosophy and Psychology, Central APA, and The Science of Consciousness conferences for criticisms and good advice that helped in the writing of this paper. I am especially grateful to David Widerker and to two anonymous reviewers for their invaluable suggestions. My writing was aided by the generous support of the Department of Philosophy and Kreitman School of Advanced Studies at Ben-Gurion University of the Negev.

${ }^{1}$ Block (in Phillips \& Block 2017, p. 169) also argues for this. 
exact same items. Neuro-computational naive realism can also answer a challenge to naive realism raised by Berger and Nanay. ${ }^{2}$

My plan for the paper is the following: After introducing naive realism, I focus on a particular version of naive realism called "selectionism". I explain why it may seem that selectionism is in tension with the existence of unconscious perceptions. I then evaluate this tension, and explain why naive realists might wish to accept a non-selectionist version of naive realism. I then develop such a version, i.e., neuro-computational naive realism. After explaining neuro-computational naive realism's advantages, I close by answering two objections.

\section{Naive realism, selectionism, and the tension with unconscious per- ceptions}

I take naive realism to minimally involves three theses. The first is:

(NR1) Perceptions are fundamentally experiences in which a subject perceives existing mind-independent items. ${ }^{3}$

(NR1), along with the assumption hallucinations are not fundamentally experiences in which a subject perceives existing mind-independent items, entails "minimal disjunctivism"-the view that perceptions and hallucinations are experiences of distinct fundamental kinds. The second thesis of naive realism is:

(NR2) The $S$ perceives $x$ relation is neither identical to, nor grounded in, representation relations. ${ }^{4}$

Note that (NR2) falls short of the much stronger thesis that perceptions lack all representational properties. (NR2) falls short of the stronger thesis by allowing the events which are perceptions to involve representational properties in addition to being obtainings of the non-representational $S$ perceives $x$ relation. I am not aware of any naive realists who accept the stronger thesis, and French $\left(2014\right.$, p. 395) explicitly denies it. ${ }^{5}$ Furthermore, it is quite clear that Brewer, Campbell, French and Martin commit themselves only to (NR2), and not to the stronger thesis. ${ }^{6}$

For naive realists, an advantage of accepting both (NR1) and (NR2) is that together they make it possible to provide certain attractive accounts of how perceptions enable us both to think about mind-independent items (see Campbell, 2002 and Putnam, 1994) and to know what is objectively the case (see McDowell, 2008 and Johnston, 2006). But I do not mean to argue about the advantages of naive realism here. Rather, I want to focus on the objection to naive realism from unconscious perceptions. To do so, I must first present the third thesis of naive realism:

\footnotetext{
${ }^{2}$ As will become clear later, neuro-computational naive realism extends and develops upon an idea of Martin's (1998). I am indebted to his work.

${ }^{3}$ See Brewer (2011, p. 93), Campbell (2002, p. 117), Snowdon (1990, p. 124), and Martin (2006, p. 354; 2004, p. 39; 2002b, p. 392-393).

${ }^{4}$ See Brewer (2011, p. 55), Campbell (2002, p. 117-118), French (2014, p. 395) and Martin (2004, p. 39).

${ }^{5}$ As far as I know, Travis (2013, p. 31) comes closest to accepting the stronger thesis, as he holds that perceptions do not represent things as being thus and so to the subject. But even Travis allows perceptions to involve certain alternative kinds of representational properties.

${ }^{6}$ See fn. 4.
} 
(NR3) A perception has the phenomenal character that it does in virtue of (i) the items perceived in the perception, and (ii) the standpoint of the perception.

The standpoint of a given perception is the set of all conditions which naive realists have suggested bear on the perception's phenomenal character, except for the items perceived. ${ }^{7}$ In the case of vision, these conditions include both extra-dermal conditions of perception, as well as conditions of the perceiver's psycho-perceptual apparatus. ${ }^{8}$ For example, the phenomenal character of your perception of a blue ball is sensitive to whether you are perceiving it from a standpoint in which it is illuminated by pink-light, or in which you suffer from certain kinds of colorblindness.

Note that (NR3) specifies neither what the perceptual standpoint itself, nor what the perceived items themselves, contribute to the determination of a perception's phenomenal character. When it comes to the separate phenomenological contributions of the standpoint and the perceived items, (NR3) is silent.

Importantly, however, some naive realists-e.g., Fish (2009, p. 75, 137-138) and Allen (2016, p. 13-14 and chp. 3)-“fill in" this silence in a very specific way. Their view (call it "selectionism") consists of two claims:

(S1) A perception has the phenomenal character that it does completely in virtue of the mind-independent items perceived in the perception.

(S2) Standpoint conditions merely select which of the many mind-independent items in the subject's environment the subject perceives.

For example, selectionism says that when you fix your gaze on a yellow and crescent shaped banana, standpoint conditions may determine that you perceive the banana's being yellow and crescent-shaped. (A banana's being yellow is, on this view, a mind-independent item.) And it is completely in virtue of your perceiving of the banana's being yellow and crescent-shaped that the banana appears yellow and crescent-shaped to you. ${ }^{9}$

It is not impossible to understand why selectionism might seem to be in tension with the existence of unconscious perceptions: That unconscious perceptions actually exist might be taken to suggest that there are actual cases in which a conscious perception and an unconscious perception are of the same mind-independent items. If this suggestion is accepted, however, it must also be accepted that it is possible for a conscious perception and an unconscious perception to be of the same mind-independent items. This, in turn, entails that it is possible for two perceptions to be of the same mind-independent items and differ in their phenomenal characters. And such a possibility is inconsistent with the selectionist claim (S1), that any perception has the phenomenal character that it does completely in

\footnotetext{
${ }^{7}$ The term "standpoint" is from Campbell (2009).

${ }^{8}$ On the extra-dermal conditions, see Campbell (2009, p. 657-658) and Brewer (2011). On the conditions of the perceiver's psychological apparatus, see Brewer (2011, chp. 5; 2013), Campbell (2002, p. 118-119) and Fish (2009, chp. 3).

${ }^{9}$ The example is adapted from Logue (2012, p. 211).
} 
virtue of the mind-independent items perceived. In this way, those who accept that unconscious perceptions actually occur might be led to reject selectionism.

\section{Evaluating the tension}

Naive realists facing the tension between selectionism and the existence of unconscious perceptions can respond in three ways. They can:

1. Deny that it is possible for a conscious perception and an unconscious perception to be of the same mindindependent items.

2. Restrict the scope of naive realism (and therefore also the scope of selectionism) to conscious perceptions.

3. Deny selectionism, and accept a non-selectionist version of naive realism.

Response \#1 is difficult to evaluate. This is partly due to the fact that the debate has so far focused more on the question of whether unconscious perceptions actually exist, than on the question of whether it is possible for a conscious perception and an unconscious perception to be of the same mind-independent items.

Regarding the former question, a growing body of empirical results suggests that unconscious perceptions do occur. In relevant studies, subjects deny perceiving a presented stimulus, and are at chance in picking the presented stimulus from a set of alternatives, suggesting that they are not consciously perceiving. At the same time, subjects nonetheless give indications that they perceive the presented stimulus. For example, they shift their attention to the stimulus, in a way that makes certain related judgments more accurate. ${ }^{10}$

Against this, Phillips (2015; Phillips \& Block 2017) has argued that the empirical results are not decisive. His argument has the form of a dilemma: Studies which purport to show that unconscious perceptions exist belong to one of two kinds. Studies of the first kind purport to show that subjects can discriminatively respond to presented features, even though the subjects are not phenomenally conscious of those features. Plausibly, since the subjects can discriminatively respond to the features, they also perceive them. However, Phillips' analysis suggests that the studies' results are consistent with the subjects' having degraded conscious perceptions of the presented features. These degraded perceptions go unreported, due to conservative reporting biases. So studies of the first kind do not establish the existence of unconscious perceptions. Turn then to studies of the second kind. These studies purport to show that subjects can perceive presented features, even though they cannot discriminatively respond to those features. Plausibly, since the subjects cannot discriminatively respond to the features, the subjects also fail to be phenomenally conscious of them. Here, Phillips' objection is different. He argues that these studies do not show

\footnotetext{
${ }^{10}$ See, e.g., (Weiskrantz, 2009), (Kouider \& Dehaene, 2007) or (Lin \& He, 2009). For a general introduction, see (Prinz, 2015). For a review of experimental methods, see (Breitmeyer, 2015).
} 
that information about the presented features is available to the individual subjects, as opposed to their perceptual systems. And, if information about the presented features is not available to the individual subjects, it is not clear that the subjects perceive the features. After all, perceptions are meant to be states of subjects (i.e., person-level states), and not merely states of perceptual systems. Thus, Phillips reasons, studies of the second kind do not establish the existence of unconscious perceptions any more than studies of the first kind. Phillips concludes that the case for unconscious perceptions is far from established.

In a response, Block (2015; Phillips \& Block 2017) has suggested that Phillips' criticisms are ad-hoc, and that converging evidence for unconscious perception comes from multiple experimental paradigms. Phillips (in Peters et al., 2017), on the other hand, has explained that much in the debate assumes controversial operational definitions of individual-level perception. The debate rages on.

I wish to take no side in this debate. My main concern is that even if Phillips is correct that the case for unconscious perceptions is far from established, the more immediate question remains open. This is the question of whether it is possible for a conscious perception and an unconscious perception to be of the same mind-independent items. To illustrate the kind of scenario I have in mind here, suppose that two subjects had visual perception systems which exhibited post-receptoral neural response patterns that tracked the exact same mind-independent items. Suppose also that this tracking causally enabled both subjects to (i) discriminate the tracked items from other nearby items, (ii) visually attend to the tracked items, (iii) visually guide various actions on the tracked items, and (iv) recognize the items as being certain ways-all in the service of the subjects' goals. Finally, suppose that exactly one of the two subjects was phenomenally conscious of the items. What is our intuitive judgment of this scenario? Well, since both subjects' perceptual systems interact with the same items in a way which enables the subjects to issue goal-serving person-level responses to the items, it is difficult to deny that the subjects enjoy genuine person-level perceptions of the items. And, since only one of the subjects is phenomenally conscious of the items, the scenario also seems to be one in which there are two perceptions of the same items, only one of which is conscious. Therefore, if this scenario constitutes a genuine metaphysical possibility, selectionism is refuted. Now, to be clear, I am not aware of a knock down argument establishing that the scenario does constitute a genuine metaphysical possibility. Still, I would not like the fate of naive realism to rest on this matter. I therefore prefer to set response \#1 aside.

Response \#2 suggests that we restrict the scope of naive realism (and therefore also the scope of selectionism) to conscious perceptions. This restriction would entitle us to replace the original selectionist thesis-"a perception has the phenomenal character that it does completely in virtue of the mind-independent items perceived in the perception"-with the following more restricted thesis: A conscious perception has the phenomenal character that it does completely in virtue of the mind-independent items perceived in the perception. On the restricted thesis, there is no inconsistency between selectionism and the possibility that a conscious perception and an unconscious perception might be perceptions of the same mind-independent items. Possible cases in which the same items are 
perceived once consciously and again unconsciously are simply not counterexamples to the restricted thesis.

I will discuss neither how Berger and Nanay (2016, p. 427-430) would object to response \#2, nor how Anaya and Clarke (2017, p. 2-3) would try to rebut Berger and Nanay's objection. This is because my reasons for avoiding response \#2 are very different than Berger and Nanay's.

Block $(2007 ; 2010)$ and Pautz $(2014 ; 2017)$ have both plausibly argued, on empirical grounds, that it is possible for two conscious perceptions to be of the same mind-independent items and differ in their phenomenal characters. Pautz in particular has argued that spectrum inversion cases-in which two subjects perceive the same items under the same extra-dermal conditions, though the items look different colors to them-are possible. This possibility of phenomenally different conscious perceptions of the same items threatens more than the original form of selectionism. It also threatens the restricted thesis that a conscious perception has the phenomenal character that it does completely in virtue of the mind-independent items perceived in the perception. So even if response \#2 does resolve the tension between selectionism and the existence of unconscious perceptions, it is of no help with Block and Pautz's arguments. Other things being equal, however, it would be better to solve both problems together, and in a unified way. ${ }^{11}$

Response \#3 remains open. I believe that it is the most attractive response. According to it, we should follow Brewer (2011), Campbell (2002), French (2014) and others in accepting a non-selectionist version of naive realism. Non-selectionist versions of naive realism allow perceptual standpoints to contribute to the determination of perceptions' phenomenal characters in ways that go beyond the identity of the perceived items. So, for instance, a perceptual standpoint might determine whether one has a watchful or steady perception (Campbell \& Cassam, 2014, pp. 28, 51), a blurry perception (French, 2014), a perception with the phenomenal character that red/green color blind subjects enjoy when they look at an apple (Brewer, 2011, p. 116), etc. We have seen no reason to think that non-selectionist versions of naive realism cannot accommodate both unconscious perceptions and the possibility of phenomenally different conscious perceptions of the same items. However, as Anaya and Clarke (2017, p. 5-6) have noted, we should do more than simply announce this. We should also constructively explain how our preferred nonselectionist version of naive realism accommodates unconscious perceptions. Furthermore, we should constructively explain how our preferred non-selectionist version of naive realism accommodates the possibility of phenomenally different conscious perceptions of the same items. I turn to these tasks next.

\section{Naive realism for unconscious perceptions}

I begin with Martin's (1998, p. 173-175) important remark that

\footnotetext{
${ }^{11}$ Some may believe that selectionism can successfully resist Block $(2007 ; 2010)$ and Pautz’s $(2014 ; 2017)$ arguments. For a long argument that selectionism cannot do so, see my (2019).
} 
to have an experience is to have a viewpoint on something: experiences intrinsically possess some subject-matter which is presented to that viewpoint. To understand such experience and what it is like, one has to understand the viewpoint on that subject-matter, and hence also to attend to the subject matter as presented to the viewpoint. ...On this view, difference in presented elements between two experiences will be sufficient for difference in their phenomenal properties.

Immediately following this remark, Martin (1998, p. 175) adds a comment on the "much stronger" thesis that "sameness and difference of phenomenal properties just are sameness and difference in presented elements":

It is doubtful that this claim is true: why cannot the ways in which things are presented in experience make a difference to what the experience is like, in addition to what is presented?

Martin is suggesting that aspects of perceptual phenomenology are not mere presentations of items. Rather, they are presentations of items in certain ways. In other words, Martin accepts a "multiple component" thesis, according to which aspects of perceptual phenomenology are complexes that have both a presented item component and a way of presentation component. Differences in either one of these two components may be sufficient for differences in a perception's phenomenal character.

I wish to elaborate Martin's multiple component thesis by making three proposals. First, I distinguish between (a) items that perceptually appear to subjects, (b) subjects' appearance properties and (c) the perceptual appearance relation. The items that perceptually appear to subjects correspond to Martin's presented items. These items are mind-independent. For example, a particular rock can perceptually appear to you various ways. So can its color or shape. Appearance properties, on the other hand, correspond to Martin's ways of presentation. To have an appearance property is to be appeared to in a certain way. For example, you can be appeared to in a greenish way, or in a cubical way. ${ }^{12,13}$ Finally, the perceptual appearance relation is the three place relation $x$ perceptually appears $W$ to $S$. This relation obtains between a subject $S$, an appearance property $W$ that $S$ instantiates, and a perceptually appearing item $x$. When $S$ stands in this relation to an item $x$ and an appearance property $W$, not only is $S$ appeared to in way $W$, but furthermore, $x$ perceptually appears in way $W$ to $S$. For example, when you stand in this relation to both a particular rock and the appearance property of being appeared to in a cubical way, not only are you appeared to in a cubical way, but furthermore, the rock perceptually appears cubical to you.

With these distinctions made, let's revisit the conception of perceptual phenomenology which Martin's remark suggests. On this conception, aspects of perceptual phenomenology are instantiations of the $x$ perceptually appears $W$

\footnotetext{
${ }^{12} \mathrm{By}$ " $S$ is being appeared to in a greenish way" I roughly mean that $S$ is appeared to in the way that I would be appeared to were I to now be confronted by a green thing under ideal conditions.

${ }^{13}$ My use of "appearance properties" is different from Genone (2014), Antony (2011), Kalderon (2011), Shoemaker (1994; 2000; 2006) and others' use of "appearance properties". On their use of the term, appearance properties are not properties that subjects can have, but properties that objects or scenes can have. More specifically, appearance properties are ways that objects or scenes appear simpliciter (as opposed to ways that they appear to a specific subject). This use of "appearance properties" should be carefully distinguished from my own.
} 
to $S$ relation. These instantiations relate subjects both to appearance properties and to perceptually appearing items. Aspects of perceptual phenomenology therefore have two components - an appearance property component, and a perceptually appearing item component. A difference in any one of these two components is also a difference in an aspect of perceptual phenomenology. For example, if a single rock perceptually appears cubical to Alice but spherical to Bob, Alice and Bob's perceptions have different phenomenologies. This is because, in the rock's perceptually appearing cubical to Alice and spherical to Bob, Alice and Bob have different appearance properties (Alice is appeared to in a cubical way, while Bob is appeared to in a spherical way). Equally, if one rock perceptually appears cubical to Alice, and another rock perceptually appears cubical to Bob, Alice and Bob's perceptions also have different phenomenologies. This is because, in the different rocks' perceptually appearing cubical to Alice and Bob, Alice and Bob have different items perceptually appear to them. ${ }^{14}$

My second proposal is that the relation $x$ perceptually appears $W$ to $S$ is intimately connected to the relation $S$ perceives $x$. The connection is that necessarily, if $x$ perceptually appears $W$ to $S$, then $S$ perceives $x$. For example, it is necessary that if a rock perceptually appears cubical to you, then you perceive the rock. Despite their intimate connection, however, if unconscious perceptions are possible, the relations $x$ perceptually appears $W$ to $S$ and $S$ perceives $x$ must be distinct. This is because $S$ 's unconsciously perceiving $x$ entails both $S$ 's perceiving $x$ and $x$ 's not perceptually appearing any way to $S$.

The importance of the second proposal is that it ensures (on the present conception of perceptual phenomenology) that perceived items make a difference to perceptual phenomenology. For as we just explained, perceptually appearing items make a difference to perceptual phenomenology. (When different rocks perceptually appear cubical to Alice and Bob, Alice and Bob’s perceptions have different phenomenologies.) So, since all perceptually appearing items are also perceived, perceived items make a difference to perceptual phenomenology too.

My third and final proposal concerns appearance properties. It states that which appearance properties a subject has, and whether she has appearance properties at all, is determined completely in virtue of her neuro-computational properties (which are a part of her perceptual standpoint). ${ }^{15}$ So, for example, whether a subject is appeared to in a cubical way, in a spherical way, or in no way at all is entirely in virtue of the subject's neuro-computational properties. $^{16}$ By "a neuro-computational property" I mean an intrinsic property of a subject, whose connections with the external world are not metaphysically necessary. Intrinsic neuro-computational properties can be either neural properties (e.g., a complex distributed neural pattern in the subject's visual system), or properties which-at

\footnotetext{
${ }^{14}$ Martin discusses and defends this conception of phenomenology in his (1998; 2002a; 2002b). Also see Campbell (2002) and Gomes \& French (2016).

${ }^{15}$ To say that one set of properties is determined completely in virtue of another set of properties does not entail that each of the properties in the first set is identical to some property in the second set. One alternative possibility is that the properties in the second set ground the properties in the first. Therefore, my proposal is compatible with multiple views about the nature of appearance properties themselves.

${ }^{16}$ External events may, of course, cause you to have the neuro-computational properties that you have. In this way, external events may also play a causal role in the instantiation of appearance properties. This is perfectly consistent with the claim that you have the appearance properties that you do completely in virtue of your neuro-computational properties.
} 
least when they have the appropriate contingent connections with the external world-implement or are involved in the implementation of some computation or algorithm. ${ }^{17}$

This final proposal may seem quite surprising. First, to accept it is to deny that your appearance properties are determined even partly in virtue of the items you perceive. Some naive realists, however, might like to insist that your appearance properties are determined partly in virtue of the items you perceive. So why am I resisting this? Second, one might reasonably think that if a property is involved in the implementation of a computation, then the property also represents something or other. So in appealing to properties which potentially represent things, am I not embracing a position which is out of step with the naive realist commitment to (NR2)? I address both these issues in order.

My reason for proposing that your appearance properties are not even partly determined in virtue of the items you perceive has to do with the aforementioned arguments by Block and Pautz. Pautz's (2014; 2017) argument in particular relies on empirical findings which suggest that similarities in taste, smell, loudness, and color experiences are well correlated with similarities in the subject's neuro-computational properties, but poorly correlated with similarities in the perceived properties. ${ }^{18}$ As Pautz explains, the most plausible interpretation of these findings is that by varying a subject's neuro-computational properties, we can ensure that the subject has whatever taste, smell, loudness and color appearance properties we wish. At the same time, varying the subject's neuro-computational properties is consistent with those varied neuro-computational properties' always tracking the same mind-independent items and always enabling the subject to issue goal-serving person-level responses to those items. Therefore, it is plausible that varying the subject's neuro-computational properties is consistent with there being no change in the totality of items that the subject perceives. In this way, Pautz's argument suggests that the totality of items that a subject perceives can be fixed, while the subject's taste, smell, loudness and color appearance properties vary freely.

The problem, then, is this: On the one hand, broadly empirical considerations suggest that the items you perceive leave your taste, smell, loudness, and color appearance properties unconstrained. I think this makes it highly implausible to propose that your appearance properties are determined partly in virtue of the items you perceive. ${ }^{19}$ On the other hand, my rival proposal, that your appearance properties are determined completely in virtue of your neuro-computational properties, has no comparable plausibility problem. Furthermore, since my proposal does not suggest that your appearance properties are determined partly in virtue one kind of factor and partly in virtue of other factors, it is also simpler and clearer. So my proposal seems preferable.

To be clear, I am not suggesting that broadly empirical considerations prove that your appearance properties are

\footnotetext{
${ }^{17}$ My use of "neuro-computational properties" follows Pautz's (2010; 2013; 2017). Like Pautz, I will not try to decide here between the various causal, semantic, syntactic or mechanistic accounts of what it takes to implement a computation or an algorithm. For a review of the different positions, see Piccinini (2017). Note that although the set of neuro-computational properties is broad enough so as not to pre-judge matters currently under empirical inquiry and dispute, it will also prove to be narrow enough to advance the purposes of the present paper.

${ }^{18}$ For correlations regarding taste, see e.g. Di Lorenzo et al. (2009). For those regarding smell, see e.g. Howard et al. (2009). For those regarding loudness, see e.g. Röhl et al. (2011). Finally, for those regarding color, see Brouwer \& Heeger (2013).

${ }^{19}$ Although, cf. Logue (2017).
} 
determined completely in virtue of your neuro-computational properties. I believe further argument concerning this mater is required, and I have attempted to provide this further argument elsewhere. ${ }^{20}$ In this paper, however, I am doing something more modest: I am merely putting forward a proposal, which I suggest is empirically plausible, appealingly simple, and therefore preferable. I should also point out that I do not mean to dismiss the possibility that certain further intrinsic properties of the subject, such as collateral intrinsic mental states or bodily features, constrain which appearance properties the subject has. If these properties constrain the subject's appearance properties in a merely causal way-i.e., by merely causing the subject to have certain complex, distributed, and disconnected neuro-computational properties-then their so doing is entirely compatible with my proposals as they stand. But if not, I accept that there would be room to consider whether a subject's appearance properties are determined partly in virtue of intrinsic properties that are not strictly neuro-computational.

Finally, having said all this, I wish to again insist on the difference between saying that your appearance properties are completely determined by your neuro-computational properties, and saying that aspects of your perceptual phenomenology are completely determined by your neuro-computational properties. Aspects of perceptual phenomenology are instantiations of the $x$ perceptually appears $W$ to $S$ relation. Appearance properties are distinct from this relation. For example, a rock's perceptually appearing cubical to you is one thing, and your being appeared to in a cubical way is another. Though the latter is completely determined by your intrinsic neuro-computational state, the former further requires you to perceive the rock.

I now turn to address the concern that my account is out of step with the naive realist commitment to (NR2), because it appeals to neuro-computational properties, which potentially represent things.

To address this concern, we should start by noting that (NR2) can only be in tension with my appeal to neurocomputational properties, if this appeal implied that the $S$ perceives $x$ relation is identical to, or grounded in, representation relations. But my appeal does not imply this, and for two reasons.

First, we should distinguish between being a property which represents something, and being a representational property. The property of being an ink stain with the shape "cat", for example, is a property which represents something, namely, cats. Nevertheless, the property of being an ink stain with the shape "cat" is not a representational property, since it is distinct from the property of representing cats. (After all, had the history of English been different, the property of being an ink stain with the shape "cat" would not have represented cats.) Now, neuro-computational properties are analogous to the property of being an ink stain with the shape "cat". Like this last property, neurocomputational properties might (at least when they have the appropriate contingent connections with the external world) represent things. However, since all representational properties of the form "representing $x$ ", where " $x$ " ranges over something external to the subject, are extrinsic properties; and since all neuro-computational properties are intrinsic properties, it follows that there is no need to worry that neuro-computational properties are extrinsic

\footnotetext{
${ }^{20}$ See my (2019).
} 
representational properties.

Second, even if the neuro-computational properties that are responsible for our appearance properties were representational properties, this would not be a problem. For there is simply no reason to hold that these neurocomputational properties are identical to, or ground, the $S$ perceives $x$ relation. ${ }^{21}$ In fact, naive realists are already committed to denying that neuro-computational properties are identical to, or ground, the $S$ perceives $x$ relation. ${ }^{22}$ So there is little risk that by appealing to neuro-computational properties my account puts (NR2) in jeopardy. ${ }^{23}$

With these clarifications made, I can call the conjunction of my three proposals with (NR1)-(NR3) "neurocomputational naive realism”. I will now argue that neuro-computational naive realism has three distinct advantages.

First, neuro-computational naive realism offers a uniform treatment of conscious and unconscious perceptions. Take conscious perceptions first. Suppose a rock $(x)$ perceptually appears cubical $(W)$ to you $(S)$. According to neurocomputational naive realism, this in virtue of your perceiving the rock while having certain neuro-computational properties. Had you failed to perceive the rock, it would not have perceptually appeared cubical to you, and your perceptual phenomenology would have been different. Similarly, had you had suitably different neuro-computational properties, you would not have had the same appearance properties, and the rock would also not have perceptually appeared cubical to you. So, again, your perceptual phenomenology would have been different. Now turn to unconscious perceptions. Suppose you $(S)$ unconsciously perceive a rock $(x)$. In such a case, in virtue of some set of neuro-computational properties of yours, you instantiate no relevant appearance properties. So you fail to stand to the rock in the relation $x$ perceptually appears $W$ to $S$. The rock perceptually appears no way to you. Neither does it perceptually appear to you simpliciter. But, had you perceived the rock while in a suitably different neurocomputational state, the rock would have perceptually appeared to you in a particular way. Generally put, if $S$ unconsciously perceives $x$ then

1. $S$ perceives $x$, but

2. In virtue of some set of neuro-computational properties of $S$ 's, $S$ instantiates no relevant appearance properties, and $x$ fails to perceptually appear to $S$ in any way.

In this way, neuro-computational naive realism offers a uniform treatment of conscious and unconscious perceptions. It therefore accommodates unconscious perceptions with no trouble.

\footnotetext{
${ }^{21}$ It is noteworthy that naive realists can deny that neuro-computational properties are identical to, or ground, the $S$ perceives $x$ relation and still assert that neuro-computational properties are part of the supervenience base for the $S$ perceives $x$ relation.

${ }^{22}$ See, e.g., Brewer (2011, p. 55) and Campbell (2002, p. 117-118).

${ }^{23} \mathrm{~A}$ related, though very different, concern is that (NR2) might be in tension with the possibility that neuro-computational properties are themselves being represented-e.g., by the subject, by some of the subject's properties or states, or by some of the properties or states of the subject's body. But this concern can also be put aside: That something or other represents neuro-computational properties implies nothing about the nature of the $S$ perceives $x$ relation. For example, nothing follows about the nature of the $S$ perceives $x$ relation from the possibility that a thought in the subject's head, or a sentence the subject writes down on a piece of paper, represent (inter alia) neuro-computational properties.
} 
The second advantage of neuro-computational naive realism is that it accommodates the possibility of phenomenally different conscious perceptions of the same items. Here it is useful to recall that Block (2007; 2010) and Pautz's (2014; 2017) arguments for this possibility assume that the same items are consciously perceived by subjects with different neuro-computational properties. But, if the same items are perceived by subjects with different neurocomputational properties, it is perfectly consistent with neuro-computational naive realism that the same items are consciously perceived by subjects with different appearance properties as well. It is therefore perfectly consistent with neuro-computational naive realism that the subjects' conscious perceptions of the same items are phenomenally different.

The third advantage of neuro-computational naive realism is that it can answer a challenge to naive realism raised by Berger and Nanay (2016, p. 431). The challenge is this: In certain optical illusions (Goodale \& Milner, 2013), S’s perception of a size or a spatial-location is highly successful, and effectively guides her fine-grained actions. At the same time, the subject's phenomenal consciousness of the size or location does not reflect what the size or location is like. For example, the size of 2-inches $(x)$ may perceptually appear 4-inch-like $(W)$ to $S$. Berger and Nanay's challenge is to offer a coherent naive realist account of such illusions. ${ }^{24}$ Happily, neuro-computational naive realism can treat these illusions just as it treats all conscious perceptions. In the example, neuro-computational naive realism would say that the 2-inch size, $x$, perceptually appears 4 -inch-like to $S$ in virtue of $S$ 's perceiving $x$ while having certain neuro-computational properties. That $S$ is appeared to in a 4-inch-like way is in virtue of $S$ 's having certain neurocomputational properties. And that $S$ perceives $x$ both partly explains $S$ 's successful actions and makes it possible for $x$ to perceptually appear some way to $S$.

\section{Two objections}

Despite neuro-computational naive realism's advantages, I suspect that some naive realists might initially be inclined to resist it. They might worry that neuro-computational naive realism is inconsistent with the following thesis, endorsed by Campbell (in Campbell \& Cassam, 2014, p. 33) and others:

(Constitution) The phenomenal characters of perceptions are constituted by mind-independent qualities of objects (such as colors, shapes and sizes).

But why would neuro-computational naive realism be inconsistent with (Constitution)? Well, one answer is this: In response to Berger and Nanay's challenge, neuro-computational naive realism suggested that a perceived size of 2-inches can appear 4-inch-like to a subject. But, if a perceived size of 2-inches does appear 4-inch-like to a subject, how could the 2-inch size be a constituent of the subject's perceptual phenomenology?! Surely it could not. And

\footnotetext{
${ }^{24}$ I follow Antony (2011), Brewer (2011), Campbell \& Cassam (2014, chp. 4), Fish (2009), Genone (2014), Kalderon (2011), and Travis (2013) in taking illusions to be perceptions of some sort. So I accept that naive realists should account for illusions.
} 
yet, (Constitution) suggests that the 2-inch size must be a constituent of the subject's perceptual phenomenology. Contradiction.

As compelling as it might initially appear, this objection is misguided. That a perceived size of 2-inches is a constituent of your perceptual phenomenology simply does not entail that that size perceptually appears 2-inch-like to you. According to neuro-computational naive realism, aspects of perceptual phenomenology are instantiations of the $x$ perceptually appears $W$ to $S$ relation. Such instantiations have the items that occupy the $x, W$ and $S$ argument places as constituents. So, if a perceived size of 2-inches appears 4-inch-like to you, then there is an aspect of perceptual phenomenology whose constituents are yourself, your property of being appears to in a 4-inch-like way, and (importantly) the perceived size of 2-inches. All this is perfectly consistent with (Constitution).

At this point, some naive realists might make a different objection. They might say that if you are appeared to in a 4-inch-like way (and not in a 2-inch-like way), then you lack "direct access" to the mind-independent 2-inch size that is before you. This lack of direct access suggests that you do not perceive the 2-inch size. Therefore, you cannot perceive the 2-inch size and also be appeared to in a 4-inch-like way (and not in a 2-inch-like way). Neurocomputational naive realism's claim to the contrary is false.

This second objection opens with the premise that "if you are appeared to in a 4-inch-like way (and not in a 2-inch-like way), then you must lack 'direct access' to the mind-independent 2-inch size that is before you'. It is this premise which is false. For if you were one of the subjects Berger and Nanay discuss, though you would be appeared to in a 4-inch-like way (and not is a 2-inch-like way), tracking by your visual perception system would enable you to effectively guide fine-grained actions on the 2 -inch size that is before you. This makes it implausible to deny that you would have direct perceptual access to the 2-inch size. Furthermore, the access would be access by you (i.e., person-level perceptual access), since it would be you who could effectively guide the fine-grained actions on the 2-inch size. So pace the objection, you can perceive the 2-inch size and also be appeared to in a 4-inch-like way.

\section{Conclusion}

I have set out to discuss the unconscious perceptions objection to naive realism. In responding to this objection, I have proposed a new non-selectionist version of naive realism - neuro-computational naive realism. In support of this new view, I argued that it offers a uniform treatment of both conscious and unconscious perceptions. I have also argued that it accommodates the possibility of phenomenally different conscious perceptions of the same items, and that it can answer a challenge to naive realism raised by Berger and Nanay. I therefore conclude that neurocomputational naive realism is a version of naive realism that merits further study. 


\section{References}

Allen, K. (2016). A Naive Realist Theory of Colour. Oxford: Oxford University Press.

Anaya, A. \& Clarke, S. (2017). Naïve realism and unconscious perception: A reply to berger and nanay. Analysis.

Antony, L. (2011). The openness of illusions. Philosophical Issues, 21, 25-44.

Beck, O. (2019). Rethinking naive realism. Philosophical Studies, 176, 607-633.

Berger, J. \& Nanay, B. (2016). Relationalism and unconscious perception. Analysis, 76, 426-433.

Block, N. (2007). Sexism, racism, ageism, and the nature of consciousness. In Consciousness, Function, and Representation, volume 1 chapter 25, (pp. 571-601). Cambridge, MA: MIT Press.

Block, N. (2010). Attention and mental paint. Philosophical Issues, 20, 23-63.

Block, N. (2015). The anna karenina principle and skepticism about unconscious perception. Philosophy and Phenomenological Research.

Breitmeyer, B. G. (2015). Psychophysical "blinding" methods reveal a functional hierarchy of unconscious visual processing. Consciousness and Cognition, 35, 234-250.

Brewer, B. (2011). Perception and its Objects. Oxford: Oxford University Press.

Brewer, B. (2013). Attention and direct realism. Analytic Philosophy, 54, 421-435.

Brouwer, G. J. \& Heeger, D. J. (2013). Categorical clustering of the neural representation of color. The fournal of Neuroscience, 33(39), 15454-15465.

Campbell, J. (2002). Reference and Consciousness. Oxford: Oxford University Press.

Campbell, J. (2009). Consciousness and reference. In B. McLaughlin, A. Beckermann, \& S. Walter (Eds.), Oxford Handbook of Philosophy of Mind (pp. 648-662). Oxford: Oxford University Press.

Campbell, J. \& Cassam, Q. (2014). Berkeley’s Puzzle. Oxford: Oxford University Press.

Di Lorenzo, P. M., Chen, J.-Y., \& Victor, J. D. (2009). Quality time: Representation of a multidimensional sensory domain through temporal coding. The fournal of Neuroscience, 29(29), 9227-9238.

Fish, W. (2009). Perception, Hallucination, and Illusion. Oxford: Oxford University Press.

French, C. (2014). Naive realist perspectives on seeing blurrily. Ratio, 27, 393-413. 
Genone, J. (2014). Appearance and illusion. Mind, 123, 339-376.

Gomes, A. \& French, C. (2016). On the particularity of experience. Philosophical Studies, 173, 451-460.

Goodale, M. \& Milner, D. (2013). Sight Unseen. Oxford: Oxford University Press, 2 edition.

Howard, J. D., Plailly, J., Grueschow, M., Haynes, J.-D., \& Gottfried, J. A. (2009). Odor quality coding and categorization in human posterior piriform cortex. Nature Neuroscience, 12, 932-938.

Johnston, M. (2006). Better than mere knowledge? The function of sensory awareness. In T. S. Gendler \& J. Hawthorne (Eds.), Perceptual Experience (pp. 260-290). Oxford University Press.

Kalderon, M. E. (2011). Color illusion. Nô̂s, 45, 751-775.

Kouider, S. \& Dehaene, S. (2007). Levels of processing during non-conscious perception: a critical review of visual masking. Philosophical Transactions of the Royal Society of London B: Biological Sciences, 362(1481), 857-875.

Lin, Z. \& He, S. (2009). Seeing the invisible: The scope and limits of unconscious processing in binocular rivalry. Progress in Neurobiology, 87(4), 195-211.

Logue, H. (2012). Why naive realism. Proceedings of the Aristotelian Society, 112, 211-237.

Logue, H. (2017). Are perceptual experiences just representations? In B. Nanay (Ed.), Current Controversies in Philosophy of Perception chapter 3, (pp. 43-56). New York: Routledge.

Martin, M. G. F. (1998). Setting things before the mind. Royal Institute of Philosophy Supplement, 43, 157-179.

Martin, M. G. F. (2002a). Particular thoughts and singular thought. In A. O’Hear (Ed.), Logic, Thought and Language, volume 51 of Royal Institute of Philosophy Supplement (pp. 173-214). Cambridge University Press.

Martin, M. G. F. (2002b). The transparency of experience. Mind \& Language, 17, 376-425.

Martin, M. G. F. (2004). The limits of self-awareness. Philosophical Studies, 120, 37-89.

Martin, M. G. F. (2006). On being alienated. In T. S. Gendler \& J. Hawthorne (Eds.), Perceptual Experience (pp. 354-410). Oxford University Press.

McDowell, J. (2008). The disjunctive conception of experience as material for a transcendental argument. In A. Haddock \& F. Macpherson (Eds.), Disjunctivism: Perception, Action, Knowledge chapter 16, (pp. 376-389). Oxford: Oxford University Press.

Pautz, A. (2010). Do theories of consciousness rest on a mistake? Philosophical Issues, 20, 333-367. 
Pautz, A. (2013). Does phenomenology ground mental content? In U. Kriegel (Ed.), Phenomenal Intentionality, , pp. ; his "Experiences are Representations: An Empirical Argument" in Bence Nanay (ed.) Current Controversies in Philosophy of Perception, 2017, pp. 23-42 chapter 11, (pp. 194-234). Oxford University Press.

Pautz, A. (2014). The real trouble with phenomenal externalism: New empirical evidence for a brain-based theory of consciousness. In R. Brown (Ed.), Consciousness Inside and Out: Phenomenology, Neuroscience, and the Nature of Experience chapter 18, (pp. 237-298). Dordrecht: Springer.

Pautz, A. (2017). Experiences are representations: An empirical argument. In B. Nanay (Ed.), Current Controversies in Philosophy of Perception chapter 2, (pp. 23-42). New York: Routledge.

Peters, M. A. K., Kentridge, R. W., Phillips, I., \& Block, N. (2017). Does unconscious perception really exist? continuing the assc20 debate. Neuroscience of Consciousness, 3, 1-11.

Phillips, I. (2015). Consciousness and criterion: On block's case for unconscious seeing. Philosophy and Phenomenological Research.

Phillips, I. \& Block, N. (2017). Debate on unconscious perception. In B. Nanay (Ed.), Current Controversies in Philosophy of Perception chapter 11, (pp. 165-192). New York: Routledge.

Piccinini, G. (2017). Computation in physical systems. In E. N. Zalta (Ed.), The Stanford Encyclopedia of Philosophy. Summer 2017 edition. URL = <https://plato.stanford.edu/archives/sum2017/entries/computationphysicalsystems/>.

Prinz, J. J. (2015). Unconscious perception. In M. Matthen (Ed.), The Oxford Handbook of Philosophy of Perception chapter 19, (pp. 371-389). Oxford: Oxford University Press.

Putnam, H. (1994). Sense, nonsense, and the senses: An inquiry into the powers of the human mind. The fournal of Philosophy, 91, 445-517.

Röhl, M., Kollmeier, B., \& Uppenkamp, S. (2011). Spectral loudness summation takes place in the primary auditory cortex. Human Brain Mapping, 32(9), 1483-1496.

Shoemaker, S. (1994). Phenomenal character. Noûs, 28(1), 21-38.

Shoemaker, S. (2000). Phenomenal character revisited. Philosophy and Phenomenological Research, 60(2), 465-467.

Shoemaker, S. (2006). On the ways things appear. In T. S. Gendler \& J. Hawthorne (Eds.), Perceptual Experience (pp. 461-480). Oxford University Press.

Snowdon, P. (1990). The objects of perceptual experience. Proceedings of the Aristotelian Society, 64, 121-150. 
Travis, C. (2013). The silences of the senses. In Perception: Essays After Frege chapter 1, (pp. 23-58). Oxford: Oxford University Press.

Weiskrantz, L. (2009). Blindsight - A Case Study Spanning 35 Years and New Developments. Oxford: Oxford University Press, 2 edition. 